\title{
FAT METABOLISM IN DIABETES MELLITUS ${ }^{1}$
}

\author{
By WILLIAM C. STADIE \\ (From the John Herr Musser Department of Research Medicine of the \\ University of Pennsylvania, Philadelphia)
}

(Received for publication August 7, 1940)

\section{Hypotheses of fat metabolism in diabetes mellitus}

The development of thought concerning the metabolism in diabetes mellitus since the classical experiments of v. Mehring and Minkowski has been formulated into two contrasting theories. Evidence of crucial character bearing upon these theories is still being actively sought for by experimenters, but it appears that the totality of this evidence is not yet sufficient to bring complete conviction to all in one direction or the other.

Briefly, these opposing theories may be stated as follows :

1. Under-utilization hypothesis. The major, if not the sole, defect in the intermediary metabolism in diabetes mellitus is that the peripheral tissue (i.e. chiefly muscle) cannot, either at all or in sufficient measure, oxidize carbohydrate without the catalytic intervention of insulin.

2. Overproduction hypothesis. Fatty acids are convertible into carbohydrates by the liver. The function of insulin is to control, directly or indirectly, the extent of this conversion; its action in the periphery, which is to catalyze the oxidation of carbohydrate, is either nil or of minor importance.

According to the first of these hypotheses, the complete diabetic subject must lose all of the energy derivable from carbohydrate and most of that from protein; hence he must fall back upon fats as the chief source of his energy requirements. According to the second hypothesis also, there is in the diabetic a profound disturbance of the normal course of fat metabolism in the liver. It therefore becomes necessary to examine the theories of fat metabolism which developed simultaneously with the growth of the above hypotheses.

There are two possible chemical mechanisms by which fats can be utilized in the periphery. These are :

\footnotetext{
1 Aided by grants from The American Philosophical
} Society and The Rockefeller Foundation.
I. Fats are utilized directly by the periphery, i.e., oxidation is initiated and completed in the muscles themselves.

II. There must be a preliminary partial oxidation in the liver to diffusible substances which are oxidizable by the muscles.

The possibility, discussed later, that both I and II are operative at the same time must also be considered. However, differences of opinion arose over the detailed mechanism of II which were expressed in the alternative hypotheses:

II-A. Fats are preliminarily oxidized in the liver to ketone bodies plus a two-carbon compound (acetic acid). In the normal subject these are completely oxidized in the periphery.

II-B. Fats are initially converted by the liver to carbohydrates as well as ketones for peripheral utilization.

II-C. Fats are completely converted in the liver to ketone bodies only.

Early in the literature the emphasis was placed upon one of these alternatives (II-A) almost to the complete exclusion of the others. The reasons for this were threefold: the ascendency of the under-utilization school, the strong position of the Knoop hypothesis of successive beta oxidation of fatty acids, and the development of the hypothesis of obligatory coupling of ketone body-carbohydrate oxidation in the periphery. The relation of these to the problem of fat metabolism in the diabetic will be briefly discussed.

\section{Hypothesis of successive beta oxidation of fatty acids}

The original experimental work of Knoop (1) upon which this hypothesis was based was confined to the study of phenyl-substituted fatty acids in which the side chain contained 5 carbons or less. When these acids were fed, the nature of the phenyl residue excreted clearly showed that these short fatty acids were oxidized at the carbon 
atom which was in the beta position to the terminal carboxyl group. In the case of phenyl valeric acid, the longest fatty acid studied, Knoop limited his conclusion to the statement that there was beta and delta oxidation but asserted nothing about the possible paired splitting off of acetic acid or other oxidized two-carbon compound. Nor did he state that the type of oxidation which he showed for these short fatty acids was a general biological reaction for the oxidation of longer fatty acids.

Dakin (2a), however, continued work with phenyl-substituted fatty acids and became convinced that "the evidence obtained" ... (indicates) ... "that five acids of the type $\mathrm{Ph}$.C.C.C.C.COOH undergo oxidation in the body in such a way that four carbon atoms are removed from the side chain in two pairs. ..." This process " may be termed successive beta oxidation" and he saw "no reason to suppose that it is not a general biochemical reaction." For then it became clear " that the catabolism of a fatty acid group, $\mathrm{CH}_{3} \cdot\left(\mathrm{CH}_{2}\right)_{n} \cdot \mathrm{COOH}$, is effected by the successive removal of two carbon groups at a time." It would necessarily follow that each molecule of fatty acid would be degraded through a succession of fatty acids each shorter by two carbon atoms than its immediate precursor. Finally one molecule of butyric acid would result which in its turn would be oxidized to one molecule of acetoacetic acid or beta hydroxybutyric acid.

Of the nature of the two-carbon compound split off little was known. It was most generally asserted to be acetic acid and as such was incorporated in schemes of fatty acid oxidation. The difficulty, pointed out by Friedmann (3), that acetic acid was markedly ketogenic in perfused livers was generally ignored. For then the fatty acids with odd numbers of carbon atoms, when oxidized by successive beta oxidation, should likewise produce acetic acid and therefore should be ketogenic. But they are not. Dakin $(2 b)$, recognizing the difficulty, avoided it by postulating the possible formation of other two-carbon oxidation products of the type of glyoxylic acid. However, nowhere in the literature are there any reports of the isolation or identification of any of these hypothetical two-carbon compounds.

\section{Hypothesis of obligatory coupling of ketone- carbohydrate oxidation}

The striking ketone body excretion by the diabetic subject and its equally striking recession following resumption of carbohydrate oxidation remained to be explained. Although there were isolated appeals for a simpler hypothesis ( $C f$., for example, von Fürth (4); Raper and Smith (5)), the hypothesis of obligatory coupled oxidation of ketone bodies and carbohydrates, initially founded upon an aphorism and not much more, dovetailed so neatly with the Knoop hypothesis that it became the almost unchallenged theory of the metabolism of fats in the diabetic for a period of forty years. The statement of this hypothesis as it became fully developed was as follows: the long even-numbered fatty acid chains $(C=>16)$ present in natural fats are oxidized by successive beta oxidation in the liver. A two-carbon compound-presumably acetic acid, which is easily oxidized by the peripheral tissues of the complete diabetic-is split off. The fatty acid molecule is thus reduced step by step to the four-carbon butyric acid. This in turn is oxidized to acetoacetic or beta-hydroxybutyric acid which cannot be further utilized by the diabetic and is excreted in toto.

If the diabetes is " incomplete" or if insulin is given, carbohydrates can be oxidized and there occurs in the periphery the chemical reaction of coupled ketone body-carbohydrate oxidation, viz.:

$$
\text { Ketones + carbohydrate }+\mathrm{O}_{2}=\mathrm{CO}_{2}+\mathrm{H}_{2} \mathrm{O} \text {. }
$$

This is the sole mechanism by which ketone bodies can be oxidized in normals or diabetics.

The reasons for the ascendency of this combination of hypotheses are easy to discern:

1. It permitted the under-utilization school of diabetic students to explain how the complete diabetic, who was losing about 70 to 80 per cent of the energy from protein as carbohydrate or ketone bodies, and 100 per cent of that from carbohydrate, could still exist. The calculations in Table I show that there was still a possible 27 to 62 per cent of the energy of the original fat in the form of a hypothetical two-carbon compound split off by the beta oxidation available for the energy requirements of the periphery. The balance was lost to the periphery either in the process of pre- 
TABLE I

The heats of combustion of oxidized derivatives of fatty acids and the calculated energy available to the periphery

1 gram mole of fat (triglyceride) $=870$ grams $=8200$ calories (typical fatty acid $=\mathrm{C}_{10} \mathrm{H}_{32} \mathrm{O}_{2}$, palmitic)

\begin{tabular}{|c|c|c|c|c|}
\hline $\begin{array}{l}\text { Substrate formed in liver } \\
\text { by partial oxidation } \\
\text { of fatty acid }\end{array}$ & Calories/Moles & $\begin{array}{c}\text { Moles/ } \\
\text { Mole of } \\
\text { fat }\end{array}$ & $\begin{array}{c}\text { Total fat } \\
\text { oalories } \\
\text { available } \\
\text { to } \\
\text { periphery }\end{array}$ & Glucogenio \\
\hline 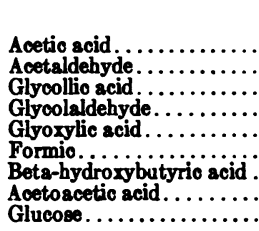 & $\begin{array}{c}209 \\
281 \\
167 \\
? \\
125 \\
63 \\
488 \\
? \\
673\end{array}$ & $\mid \begin{array}{l}3 \times 6^{*} \\
3 \times 6^{*} \\
3 \times 6^{*} \\
3 \times 6^{*} \\
3 \times 6^{*} \\
3 \times 12^{*} \\
3 \times 4 \dagger \\
3 \times 4 \dagger \\
3 \times 2.67 \ddagger\end{array}$ & $\begin{array}{c}\text { per cent } \\
46 \\
62 \\
37 \\
27 \\
27 \\
72 \\
68\end{array}$ & $\begin{array}{l}\text { No } \\
\text { No } \\
\text { sSee footnote } \\
\text { SSer footnote } \\
\text { See footnote } \\
\text { No } \\
\text { No } \\
\text { No } \\
\text { Yes }\end{array}$ \\
\hline
\end{tabular}

* By successive beta oxidation hypothesis: 1 mole fatty acid $=1$ mole ketone +6 mole substrate.

† By multiple alternate oxidation hypothesis: 1 mole fatty acid $=4$ mole substrate.

$\ddagger$ Hypothetical maximum yield per mole fat.

$\$$ No information found that these compounds are intermediates in fat catabolism. None have been clearly demonstrated to be glucogenic.

liminary oxidations in the liver or in the form of unoxidizable ketone bodies. The position of the complete diabetic was indeed quite precarious, but it was conceivable that his energy requirements could be met by such a mechanism. Curiously enough, as is seen from the table, the formation of acetic acid or glyoxylic acid, which are those most frequently advocated, would yield the least amount ( 27 to 46 per cent) of the energy of the original fat to the periphery.

2. It allowed this school to avoid postulating the formation of carbohydrate from fats, since a compound other than carbohydrate, but presumably oxidizable by the diabetic, was formed in the liver.

3. It allowed of a ready explanation, which appeared to be quantitative, of the marked influence of carbohydrate utilization upon urinary ketone body excretion.

The position of the over-productionists was less clear. Obviously, they could hardly espouse the obligatory coupling hypothesis, for then ketonuria would never occur, since by assumption abundance of carbohydrate is oxidized in the periphery. It was natural, then, that they concerned themselves with experiments designed to show that the ketone bodies were oxidized in the periphery without coupling with carbohydrate oxidation $(6,7)$. The abnormal fat metabolism in diabetes could more easily be explained by postulating that there occurred in the liver the reaction:

$$
\begin{aligned}
& \text { Fatty acids }+ \text { oxygen }=\text { ketone bodies }+ \\
& \text { glucose }+ \text { (two-carbon compound } ?)
\end{aligned}
$$

The exact stoicheiometric proportions of this reaction were never clearly defined. The important assumption was made that this reaction was controlled directly or indirectly by insulin. In diabetes mellitus, therefore, it ran to excess, resulting in "over production" of ketone bodies and glucose. The effect of what the under-utilizationists call a " resumption of carbohydrate oxidation in the periphery" in causing a recession of ketonuria and glycosuria could just as readily be explained by asserting that under the same conditions the above reaction was inhibited. However, despite the fact that the hypothesis of successive beta oxidation was the accepted explanation of the mechanism of fat oxidation in the liver, certain of its implications were ignored, viz.:

1. All the conceivable two-carbon oxidized compounds derivable from fatty acids (Table I) have either been shown to be aglucogenic or else have never been shown to be intermediaries in the catabolism of fat. It was necessary to fall back upon the assumption that the four-carbon residues of the oxidation of fatty acids were the immediate precursors of glucose, although there was no conclusive evidence that this was so. Butyric acid itself, which is known to be glycogenic in the liver $(8 b)$, has never been shown to be an intermediate in the hepatic catabolism of fat. Nor is there any evidence that the ketone bodies themselves are glycogenic. The recent experiments of WeilMalherbe (9) showing that acetoacetic acid is converted into glucose by the kidney have not been confirmed (10).

2. Aside from this, there is another difficulty if only the residual four-carbon compounds of fatty acid are convertible to glucose. For then both the ketone bodies and glucose originating from fatty acids must come entirely from these residues and the maximum grams $(G)$ of glucose which could be obtained from the catabolism of 
$F$ grams of fat when $K$ grams of beta-hydroxybutyric acid are excreted:

$$
\frac{G}{180}=\left(\frac{F}{870} \times 3 \times \frac{4}{6}\right)-\left(\frac{4}{6} \times \frac{K}{104}\right)
$$

or $G=0.41 F-1.15 K$.

In other words, there should be in the diabetic an inverse relation between glucose and ketone excretion, and in the limit, according to the equation, glucose excretion from fats should be zero when the grams of urinary ketones is approximately $1 / 3$ of the grams of total fat catabolized. But no such relations have ever been remotely suggested in innumerable metabolic studies of diabetes mellitus. These considerations logically require that the over-productionists abandon the hypothesis of successive beta oxidation of fatty acids as incompatible with their own views and propose another, although to date no convincing substitute has been suggested.

\section{Evidence against the combined hypotheses}

A retrospect of the literature shows that, long before outspoken doubts began to appear, there was evidence which was completely at variance with the successive beta oxidation and obligatory coupling hypotheses when these were carried to their logical conclusions. For example, it was long known that the partition of fats in the livers of fasting normal animals who must be subsisting largely on fats failed to reveal any of the lower fatty acids which were supposed to be formed by degradation of the higher ones. The major portion of the fatty acids contained carbon atoms $=>16$. Small amounts ( 1 to 2 per cent) of myristic $\left(C_{14}\right)$ and lauric $\left(C_{12}\right)$ were found, but essentially no acids with fewer carbon atoms. In particular, butyric acid should have been formed in large amounts by the livers of diabetic subjects with severe ketosis and, being freely diffusible, should have appeared in the urine. There, as Hurtley (11) pointed out, its presence should long ago have been revealed by its odor alone $!^{2}$ Still more convincing was the evidence in the working diabetic, particularly the exercising de-

2 Butyric acid at pH 5 to 7.4 is easily detectable by its odor at $0.01 \mathrm{M}$. This is approximately $1 / 20$ of the urinary concentration of ketone bodies frequently observed in severe ketosis. pancreatized animal. ${ }^{3}$ Since these animals were presumably oxidizing no carbohydrate, they should oxidize no ketone bodies. Hence, during exercise, the excess ketone body excretion over the basal excretion could easily be calculated from the excess fat metabolism. But there was no doubt, as found by many observers, that there was essentially no increase of ketone body excretion during exercise despite large increases of fat metabolism. This is clear indication that large amounts of fats were completely utilized without coupling with carbohydrate oxidation. This one fact alone was completely at variance with the obligatory coupling hypothesis and should have forced its abandonment at once.

The more systematic attack upon the Knoop hypothesis may be said to have begun with Hurtley's paper (11). The absence of the lower fatty acids in the livers of diabetics dying of coma led him to reject the Knoop hypothesis and propose instead the hypothesis which became known as the multiple alternate oxidation hypothesis (II-C). According to this, fatty acids are oxidized simultaneously along the whole length of the carbon chain at alternate carbon atoms with complete disruption into ketone bedies according to the scheme:

$\mathrm{CH}_{3} \ldots \mathrm{CH}_{2} \cdot \mathrm{CH}_{2} \cdot \mathrm{CH}_{2} \cdot \mathrm{CH}_{2} \cdot \mathrm{CH}_{2} \cdot \mathrm{CH}_{2} \cdot \mathrm{CH}_{2} \cdot \mathrm{CH}_{2}$ $\ldots \mathrm{COOH}+\mathrm{O}_{2}=\mathrm{CH}_{3} \ldots \mathrm{CO} \cdot \mathrm{CH}_{2} \cdot \mathrm{CO} \cdot \mathrm{CH}_{2}$.$\mathrm{CO} . \mathrm{CH}_{2} \cdot \mathrm{CO} . \mathrm{CH}_{2} \ldots \mathrm{COOH}+\mathrm{O}_{2}=4 \mathrm{CH}_{3}$.CO.$\mathrm{CH}_{2} \cdot \mathrm{COOH}$.

A typical fatty acid such as palmitic $\left(\mathrm{C}_{16} \mathrm{H}_{32} \mathrm{O}_{2}\right)$ would accordingly yield not one but four molecules of ketone bodies. Jowett and Quastel (13) determined ketone body formation by liver slices in the presence of various fatty acids. The yield of ketone bodies from the higher fatty acids $\left(\mathrm{C}_{8-10}\right)$ in comparison to that from the lower ones brought them to the conclusion that the oxidation went by way of multiple alternate oxidation. Deuel, Hallman, Butts, and Murray (14) fed the ethyl esters of fatty acids up to $C_{18}$ to fasting rats. Comparison of the rates of excretion of ketone bodies makes it appear unlikely that successive beta oxidation alone is responsible for the degradation of the fatty acids. For example, in the case

8 See for example Barker's (12) recent experiments on exercising depancreatized dogs. 
of caprylic acid $\left(\mathrm{C}_{8}\right)$, they concluded that delta oxidation as well as beta oxidation occurred so that two acetoacetic acid molecules would result. In the case of palmitic and stearic acids their results were more difficult of interpretation, but they concluded that three or possibly four acetoacetic acid molecules might result from one molecule of fatty acid. Their conclusion was that in the case of the higher fatty acids $\left(\mathrm{C}_{8}-\mathrm{C}_{18}\right)$ their oxidation proceeded according to the hypothesis of multiple alternate oxidation.

Blixenkrone-M $\phi 1$ ller ( $8 a$ ) perfused the livers of diabetic cats and compared the total oxygen consumption with the ketone formation. He found that it was possible to explain the low oxygen to ketone ratio only by assuming that four molecules of ketones were formed per molecule of fatty acid oxidized. Stadie, Zapp, and Lukens (15a) studied the formation in vitro of ketone bodies by slices from the livers of diabetic cats. They compared the experimentally observed ratio of oxygen uptake to ketone formation with the theoretical ones calculated according to the Knoop hypothesis and the multiple alternate oxidation hypothesis. They found (Table II) that, when oxygen uptake

TABLE II

The calculated and observed ratios of hepatic oxygen uptake to ketone formation in the diabetic animal (15a)

\begin{tabular}{lcc}
\hline \hline Hypothesis & $\begin{array}{c}\text { Equation for oxidation of a typical } \\
\text { higher fatty acid (palmitic) }\end{array}$ & Ratio \\
\hline Knoop & $\mathrm{C}_{16} \mathrm{H}_{32} \mathrm{O}_{2}+6 \mathrm{O}_{2}$ & $\mathrm{O}_{2}:$ ketones \\
$=\mathrm{C}_{4} \mathrm{H}_{8} \mathrm{O}_{2}+6 \mathrm{CH}_{3} \mathrm{COOH}$ & $6: 1$ \\
$\begin{array}{c}\text { Multiple } \\
\text { alternate } \\
\text { oxidation } \\
\begin{array}{c}\text { Observed in 6 } \\
\text { diabetic cats }\end{array}\end{array}$ & $\mathrm{C}_{16} \mathrm{H}_{32} \mathrm{O}_{2}+5 \mathrm{O}_{2}=4 \mathrm{C}_{4} \mathrm{H}_{8} \mathrm{O}_{3}$ & $1.25: 1$ \\
\hline
\end{tabular}

was corrected for carbon dioxide formation and for the oxygen required for the deamination of amino acids, the ratio did not differ significantly from that calculated by the latter hypothesis. Stadie, Zapp, and Lukens (15b) added further evidence at variance with the hypothesis of successive beta oxidation which predicts that some oxidized two-carbon compound, presumably acetic acid, should be formed from the higher fatty acids. Acetic acid formation should be approximately six times the ketone body formation.
Nevertheless, in slices from the livers of diabetic cats they could find no trace of acetic acid formation, although the ketone body formation was large. In addition, they found that with liver slices actively producing ketone bodies, the molecular ratio of ketone body increase to fatty acid decrease was in accordance with the hypothesis of multiple alternate oxidation rather than that of successive beta oxidation (10).

\section{Present position of the successive beta oxidation hypothesis}

The totality of the evidence cited above appears to be convincing proof that the major portion of fatty acid oxidation in the liver occurs in such a way that the entire fatty acid molecule is completely oxidized to ketone bodies. It is not intended to imply that beta oxidation does not occur. Indeed, the original experiments of Knoop and of Dakin are strong proofs that it does. More recently Stetten and Schoenheimer (16), using deuterium, have shown that palmitic acid $\left(C_{18}\right)$ can be degraded to a small extent step-wise to lauric $\left(\mathrm{C}_{14}\right)$ and myristic $\left(\mathrm{C}_{12}\right)$ acids. The point to be emphasized is that the original implication of the successive beta oxidation hypothesis, namely, that large amounts of intermediary fatty acids down to acetic acid are formed in the liver by oxidation of the long-chain fatty acids, is no longer in conformity with the experimental facts. Successive beta oxidation, if it occurs, must account for only a small part of the total fatty acid oxidation in the liver; most of it appears to be accounted for by multiple alternate oxidation.

Concerning the mechanism by which multiple alternate oxidation is brought about, nothing can be said. It is worth while remarking, however, that the conception that there is an enzyme which will " fit" a large triglyceride molecule and cause its complete disruption into ketone bodies without the formation of intermediates is not $a$ priori improbable. An analagous case would be that of glycogen whose molecule is much larger (16-18 glucose residues) and yet is rapidly broken down to glucose-1-phosphate by a specific enzyme without the formation of intermediary polysaccharides (17). 
The production of carbohydrates from fats by the liver

The conversion of fatty acids into carbohydrates by the liver would supply the muscles with an oxidizable derivative of fat other than ketone bodies. The evidence pro and con has been recently reviewed by Mitchell (18) and Soskin (19). Evidence in favor of this hypothesis has been, as a rule, indirect and circumstantial. Such direct proof as is in the literature has usually failed of confirmation. Stadie, Zapp, and Lukens (15a) moreover, showed that this conversion did not occur in the livers of diabetic cats. With liver slices they found that the summation of the respirations for the main oxidative process occurring in the liver was essentially equal to the total observed oxygen uptake.

\section{TABLE III}

The oxidative metabolism of liver slices from 6 depancreatized cats (15a)

\begin{tabular}{|c|c|}
\hline $\begin{array}{l}\text { Oxidative process } \\
\text { Deamination of amino acids ..... } \\
\text { Carbon dioxide formation ....... } \\
\text { Ketone body formation ........ }\end{array}$ & $\begin{array}{l}\text { Mean oxygen uptake per } \\
\text { gram liver per hour } \\
\text { micromoles } \\
8.2 \pm 1.2 \\
. \quad 28.0 \pm 5.0 \\
6 \quad 63.0 \pm 4.0\end{array}$ \\
\hline $\begin{array}{l}\text { Sum of known oxidations......... } \\
\text { Total observed oxygen uptake... }\end{array}$ & $\begin{array}{l}99.2 \pm 6.5 \\
\cdots \quad 87.5 \pm 4.0\end{array}$ \\
\hline Difference unaccounted for . ..... & $.-11.7 \pm 7.6^{*}$ \\
\hline
\end{tabular}

It is obvious that fatty acid (e.g. palmitic) requires oxygen for its conversion to carbohydrate. The maximum 4 yield would be according to the equation:

$$
\mathrm{C}_{16} \mathrm{H}_{32} \mathrm{O}_{2}+7.0 \mathrm{O}_{2}=2.67 \mathrm{C}_{6} \mathrm{H}_{12} \mathrm{O}_{6} \text {. }
$$

Thus $1 \mathrm{uM}$ of $\mathrm{O}_{2}$ would suffice for the production of $0.38 \mathrm{uM}$ of glucose. Now, the average excretion of glucose in Stadie, Zapp, and Lukens' series of cats ( 1 to 4 hours before the actual experiment with the liver slices) was $1100 \pm 167 \mathrm{uM}$ per

4 It is frequently stated in the literature, apparently upon entirely hypothetical grounds, that the reaction for this conversion has a respiratory quotient of 0.3 , viz.,

$$
\mathrm{C}_{18} \mathrm{H}_{82} \mathrm{O}_{2}+10 \mathrm{O}_{2}=2.2 \mathrm{C}_{6} \mathrm{H}_{12} \mathrm{O}_{6}+3 \mathrm{CO}_{2}+3 \mathrm{H}_{2} \mathrm{O} \text {. }
$$

Then 1 mole of oxygen would be equivalent to only 0.22 mole of glucose. The difficulty in balancing the oxygen uptake in the liver against the hypothetical glucose formation would become even greater. $\mathrm{kgm}$. cat per hour. Or, since the average weight of the liver is 30 grams per $\mathrm{kgm}$., there would be required approximately $97 \mathrm{uM}$ of oxygen per grams of liver per hour to produce this amount of glucose from fatty acids. But there was no oxygen whatever available in the metabolism of the diabetic liver slice for this conversion. This experiment alone, even if there were no others available, is convincing proof that the conversion of fatty acids to glucose does not occur in the diabetic liver. In the case of fasted phlorhizinized rats in which there was marked glucose and ketone-body excretion, they found the same oxygen balance with liver slices as in the diabetic cats (10). They also showed by direct analysis that there was no gluconeogenesis attributable to fat by liver slices from diabetic cats (10).

\section{Direct utilization of ketone bodies by the diabetic}

The above discussion makes it clear that the chief oxidation products of fatty acids in the liver are the ketone bodies. The calculations in Table I show that more than 70 per cent of the original energy of fat still resides in these ketone bodies and the question arises as to whether this energy is available to the peripheral tissues of the diabetic. The evidence for the answer that the diabetic can abundantly utilize ketone bodies in the periphery is completely convincing. Stadie, Zapp, and Lukens (15a) reviewed the evidence on this problem and added their own. Table IV gives calculations from data in the literature of the utilization of ketone bodies by the peripheral tissues of normal and diabetic animals. An inspection of this table shows the following:

1. Under basal conditions the diabetic animal can utilize sufficient ketones to furnish a large part, if not the whole, basal energy requirements.

2. The potential capacity for utilization under conditions of $(a)$ work or $(b)$ with high blood ketone concentration (induced by injections of ketones) is 4 to 6 times the basal utilization.

In other words, it is apparent that, provided the production of ketones from fatty acids by partial oxidation in the liver is sufficient, the diabetic could subsist practically entirely upon ketone bodies, even under conditions of severe exercise. Furthermore, this oxidation of ketone bodies presumably is completely independent of carbohydrate 


\section{TABLE IV}

Calculations from data in the literature of ketone body utilization by the peripheral tissues of the normal and diabetic animal

Chaikoff and Soskin (6)

By measurement of rate of disappearance of injected ketones from blood of :

Diabetic eviscerated dogs . . . . . . . $29 \pm 1.0$

Normal eviscerated dogs........... $34 \pm 5.5$

Friedemann (20)

By measurement of ketone body excretion in eviscerated dogs when injected with very large amounts of acetoacetate.... Maximum $120^{*}$

Blixenkrone-Møller (8)

By comparison of ketone formation of perfused diabetic cat livers with prior

ketone excretion................

By measurement of rate of disappearance of ketone bodies from blood perfused through:

Resting hind limbs of normal and diabetic cats $\ldots \ldots \ldots \ldots \ldots \ldots \ldots$

Working hind limbs of normal and diabetic cats................. $130 \pm 6.7^{*}$

Dye and Chidsey (21)

Injection of acetoacetate at high rate into nephrectomized-depancreatized dogs... Maximum 180*

Stadie, Zapp, and Lukens (15a)

(1) By comparison of ketone formation by diabetic cat liver slices with prior urinary ketone body excretion

(2) By measurement of ketone body utilization of normal and diabetic muscle mince in presence of added acetoacetate................

(3) By measurement of ketone body utilization by diabetic cat muscle mince simultaneously equilibrated

(4) By measurement of the portalhepatic ketone body difference of diabetic cats............... $30 \pm 9.8$

Mean basal ketone utilization . .... $32 \pm 3.1$

Equivalent in grams of fat ........ $2.3 \pm 0.2$

* Excluded from basal mean.

oxidation. The hypothesis of obligatory coupling of ketone-body-carbohydrate oxidation becomes, therefore, not only unnecessary, but indeed difficult, if not impossible, of retention.

\section{The calculation of the ketogenic-antiketogenic ratio as support of the obligatory coupling hypothesis}

There still remained in the minds of the students of diabetes the possibility that there is a definite molecular ratio between carbohydrate oxidized and ketone bodies oxidized. This idea stemmed from numerous calculations in the literature of the so-called ketogenic-antiketogenic ratio in diabetes mellitus. It remains, therefore, to re-examine the calculations and the assumptions upon which they are based.

The assumptions are clearly stated by Shaffer (22): “. . . The hypothesis states that antiketogenesis in the human subject is based upon a ... ketolytic reaction in the body between acetoacetic acid, the first formed of the acetone bodies and a derivative of glucose (or of other antiketogenic substances), the compound being further oxidized, but that failing to react with ketolytic substance, acetoacetic acid is resistant to oxidation, accumulates, and . . . is excreted. . . . The fact that one finds at the threshold of ketosis an approximately constant ratio between the number of molecules of the precursors of acetoacetic acid and of glucose in the metabolic mixture, must mean that the further oxidation of acetoacetic acid constantly taking place under normal conditions is accomplished through a chemical reaction with a derivative of glucose. . . ."

The best way to test the hypothesis by means of the quantitative data which are available is to set it up in the form of an equation. It has been frequently emphasized in the literature that the interrelations of ketones and carbohydrates in the intermediary metabolism of the diabetic can only be properly evaluated if the amounts of fat, protein, and carbohydrate in the metabolic mixture are determined by calorimetric methods. Let the partition of the metabolic mixture be:

$K=$ Total $\mathrm{mM}$. of ketone bodies formed from total fat and protein catabolism. (The ketone bodies derived from fat are calculated assuming 1 molecule of ketone body per mole of fatty acid.)

$U=\mathrm{mM}$. of ketone bodies utilized.

$A=$ mM. of " antiketones" oxidized.

$E=\mathrm{mM}$. of ketone bodies excreted.

$r=$ " ketogenic-antiketogenic" ratio: a small whole number ( 1 or 2 ).

According to the hypothesis, there occurs in the periphery as the sole mechanism by which ketones can be utilized the reaction:

$$
\text { Ketones }+ \text { antiketones }+\mathrm{O}_{2}=\mathrm{CO}_{2}+\mathrm{H}_{2} \mathrm{O} \text {. }
$$


The total number of ketone body molecules formed in the liver by partial oxidation of fatty acids which can be utilized in the peripheral tissues of either the normal or the diabetic subject can never exceed $r \times A \mathrm{mM}$. Accordingly, if ketone bodies are produced in excess of this value they will be excreted. These relations are expressed by the equation:

$$
U=K-E=r \times A .
$$

There are three ways in which the data obtained from subjects with diabetes mellitus can be applied to the equation:

1. By the selection of conditions where $E$ is just a little more than zero. Then it may be assumed (practically) that

$$
K=r \times A
$$

and $r$ may be calculated when $K$ and $A$ are known from the metabolic mixture. This method was called the "measurement of the ketogenic-antiketogenic ratio at the ketone body threshold." However, the definition of "ketone threshold" is somewhat arbitrary and the values of $r$ obtained by different observers using this method or by the same observer in different cases were found variant. This was explained away by supposing an "unequal distribution" of metabolites so that in some places glucose molecules were oxidized without encountering ketone bodies and hence were "wasted" as ketolytic agents, while in other cells or localities ketone bodies formed without the possibility of encountering glucose molecules and hence accumulated.

2. Patients with definite excess of $K$, as indicated by marked ketonuria, were selected, and the observed ketone body excretion compared with that calculated by the equation ( $r$ being assigned a value of 1 or 2 ) :

$$
E=K-r \times A \text {. }
$$

Unfortunately $E$ is the small difference of two large numbers. Hence the approximate agreement of the small observed and calculated $E$ values was considered sufficient even though, as was frequently found, they differed from each other by several hundred per cent.

3. In patients with definite excess of $K$ the statistics of the equation

$$
U=r \times A
$$

can be calculated. This is by far the best method since the statistical calculations would constitute an objective test of the equation and the hypothesis upon which it is based. Oddly enough, it appears never to have been used.

Fortunately, there is in the literature a sufficient amount of the necessary data for re-testing this hypothesis in subjects with diabetes mellitus. The cases are all classical ones, reported in the literature before the advent of insulin when marked ketonuria was, of necessity, a frequent accompaniment of the disease. Similar data on human diabetics will in all probability never be obtained again, since it is unlikely that patients with marked ketonuria will be allowed to remain untreated over long periods of time.

The assumptions made in calculating the data are :

1. The metabolic mixture as represented by the calories of protein, fat and carbohydrate calculated by the original authors is assumed to be correct.

2. The conversion of calories into ketones and "antiketones" is made by the use of the factors given in Table V.

3 . In testing the obligatory coupling hypothesis as expressed by equation (1), the original assumption that one fatty acid molecule yielded one ketone body molecule was adhered to. The employment of the $4: 1$ ratio as required by the multiple alternate oxidation hypothesis, however, would make no difference in the conclusions drawn from the analysis of the data.

$$
\begin{aligned}
& \text { TABLE } \mathbf{v} \\
& \text { Factors converting calories of metabolic mixture into } \\
& m M \text {. of ketones and "antiketones" } \\
& \text { 'Factor } \\
& \text { Fat on basis of } 1: 1 \text { ratio } \ldots \ldots .0 .363 \quad 0.121 \\
& \text { Fat on basis of } 4: 1 \text { ratio ........45 }
\end{aligned}
$$

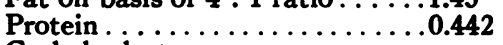

$$
\begin{aligned}
& \text { Carbohydrate.............. }
\end{aligned}
$$

Factor converting $\mathrm{mM}$. of ketone bodies into grams of original fat $=0.0726$ (on basis of 4 moles of ketone per mole of fatty acids). (Average molecular weight of fat $=870$.)

\section{Presentation of data}

1. Cases of diabetes mellitus with marked ketonuria (i.e. $=>10 \mathrm{mM} . /$ day). In this type of case, since there is an excess of ketone forma- 

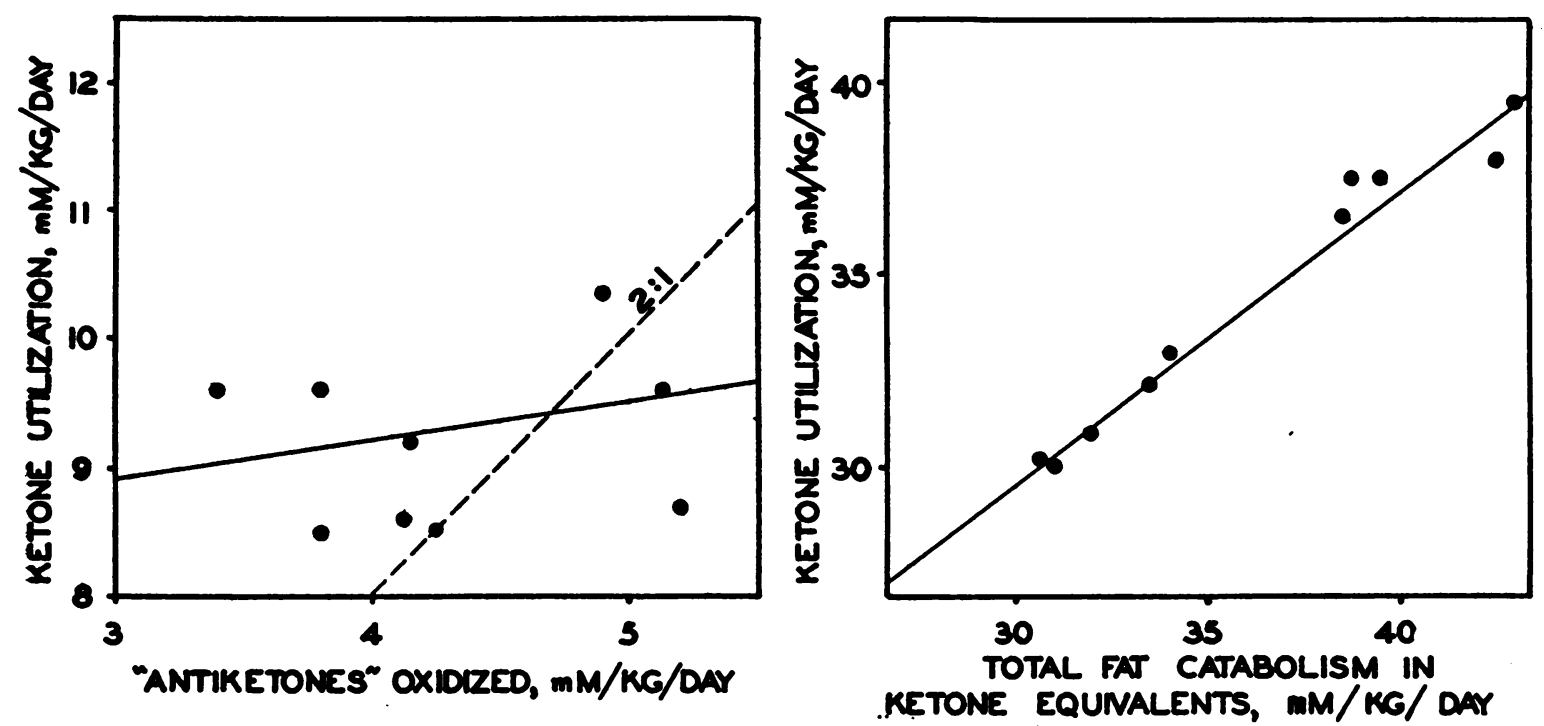

Fig. 1. Diabetes Meulitus, Case No. 740 (Joslin, 1915)

$A$. Ketone utilization as a function of "antiketones" oxidized. Correlation $=0.27 \pm 0.17 ; K: A$ ratio $=0.27 \pm$ 0.30 ; intercept constant $=8.9 \pm 0.5 \mathrm{mM} . / \mathrm{kg}$./day.

$B$. Ketone utilization as a function of total fat catabolism. Correlation $=0.99 \pm 0.04 ; k=0.75 \pm 0.04 ; U_{0}=$ $28.0 \pm 2.1 \mathrm{mM} . / \mathrm{kg} . / \mathrm{day}$.

tion, it is possible to determine whether the data are in accord with the equation:

$$
U=K-E=r \times A \text {. }
$$

In order to present the data briefly, the observations have been plotted for each individual case. The statistical analyses accompany each plot and for convenience of comparison these statistics are collected in a summarizing table.

Correlation coefficients, regression coefficients, etc., together with their standard errors, are calculated according to standard methods ( $C f$. Dunn, H. A., Physiol. Rev., 1929, 9, 215).

Case number 740, Diabetes mellitus (23), (Figure 1A). Moderate ketonuria ( $=>5$ grams beta hydroxybutyric acid per day). The dashed line is calculated by the equation $U=2 A$. The agreement of this line with the observed points is specious since the correlation coefficient is $0.27 \pm 0.17$ (not significant) and the value of $r=$ $0.27 \pm 0.30$ (i.e. without significant relation to the hypothetical value of 2). Moreover, $U$ when $A=0$ (i.e. when no antiketones are oxidized) is $8.9 \pm 0.5 \mathrm{mM}$. per $\mathrm{kgm}$. per day instead of 0 . The hypothesis gains no support from this case.

Bessie B., Diabetes mellitus (24), (Figure 2A). Ketonuria slight to moderate (beta hydroxybutyric acid 1 to 17 grams per day). The dotted line is theoretical for
$U=2 A$. It bears no significant relation to the observed points. There is no significant correlation (coefficient $=$ $-0.40 \pm 0.30$ ) and the statistical (heavy) line shows a negative value of $-0.43 \pm 0.35$ instead of a value of 1 or 2. There is an appreciable utilization of ketones (13.8 $\pm 1.7 \mathrm{mM}$. per $\mathrm{kgm}$. per day) when the "antiketones" oxidized are zero.

Kramer, Diabetes mellitus (22), (Figure $3 A$ ). Severe ketonuria (28 to 102 grams per day of beta hydroxybutyric acid). There is no significant correlation $(-0.10 \pm 0.29)$. The theoretical lines for $U=A$ and $U=2 A$ have no significant relation to the observed points. The statistically calculated value of $r$ is $0.10 \pm$ 0.29 and has no relation to the hypothesis.

Cyril K., Diabetes mellitus (25), (Figure 4A). Moderate to severe ketonuria (beta hydroxybutyric acid $=11$ to 88 grams per day). Of all the cases in this group the dotted line for the theory $U=2 A$ shows the best apparent agreement to the "eye." But this agreement is found to be specious when the statistical analysis is considered. For then the true equation for the observations is found to be

$$
U=5.6 \pm 1.2=(0.72 \pm 0.39) A
$$

rather than

$$
U=0+2 A \text {. }
$$

The statistical value of $r=0.72 \pm 0.39$ is significantly different from the supposed value of 2 . Moreover, $U$ should be 0 when $A$ (antiketones oxidized) is 0 . But it 
$2 A$

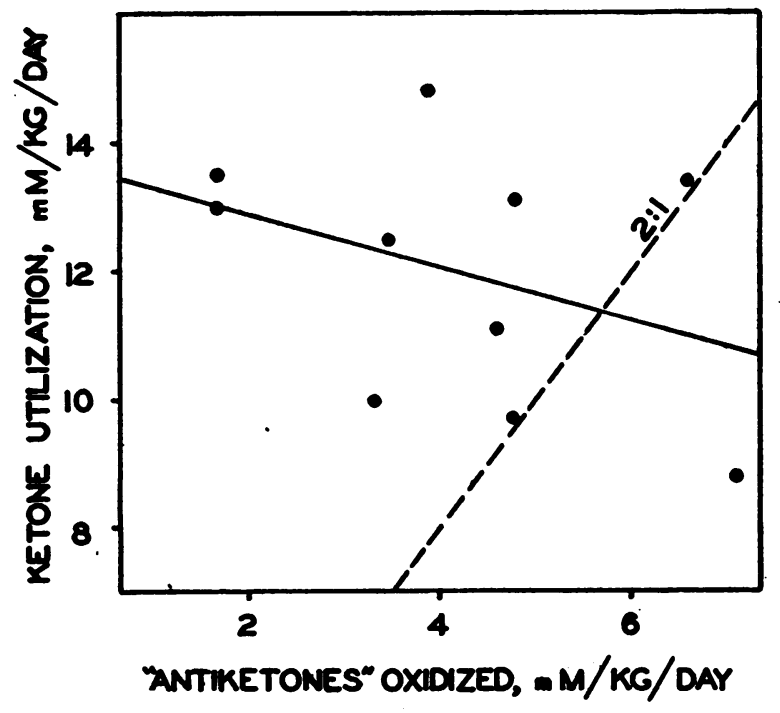

$2 B$

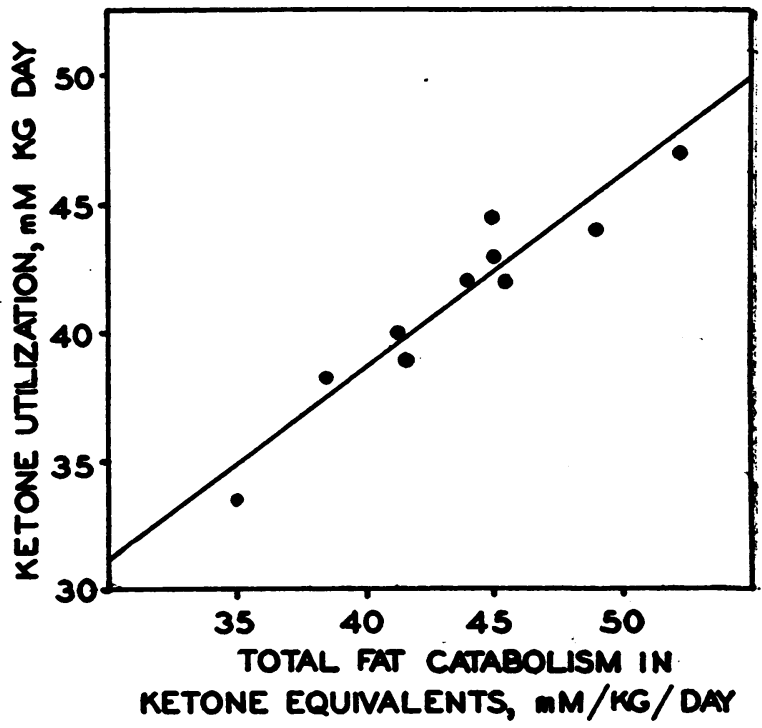

Fig. 2. Diabetes Melitus, Bessie B. (Wilder, Boothby, and Beeler, 1922)

$A$. Ketone utilization as a function of "antiketones" oxidized. Correlation $0.40 \pm 0.30 ; K: A$ ratio $=-0.43 \pm$ 0.35 ; intercept constant $=13.8 \pm 1.7 \mathrm{mM}$. $/ \mathrm{kg}$./day.

$B$. Ketone utilization as a function of total fat catabolism. Correlation $0.95 \pm 0.03 ; k=0.75 \pm 0.09 ; U_{0}=$ $34.5 \pm 4.6 \mathrm{mM} . / \mathrm{kg} . / \mathrm{day}$.

$3 A$

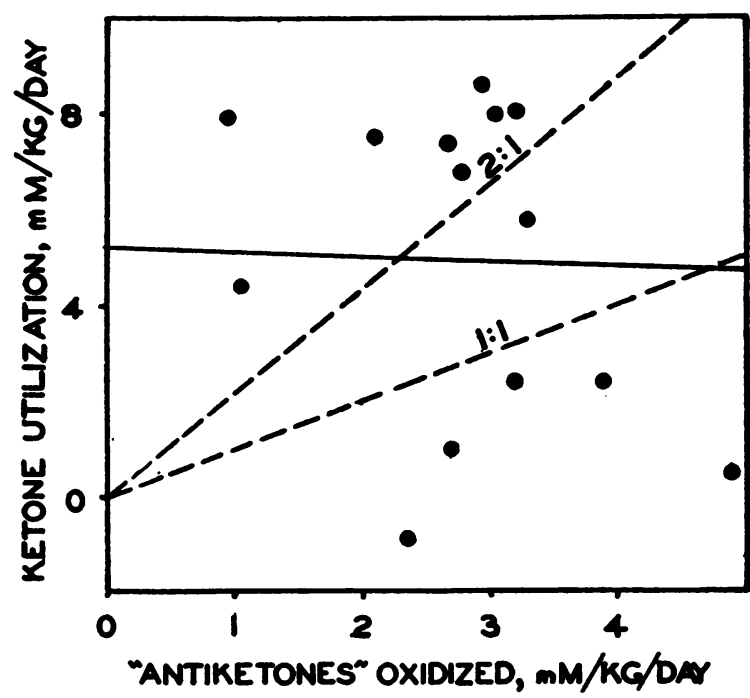

$3 B$

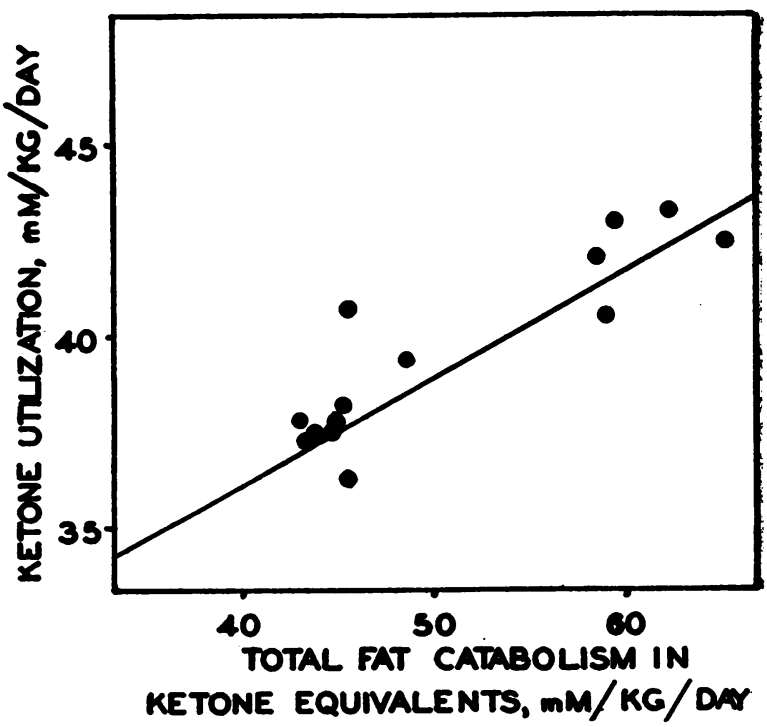

Fig. 3. Diabetes Meluitus, Kramer (Shaffer, 1922)

$A$. Ketone utilization as a function of "antiketones" oxidized. Correlation $=-0.10 \pm 0.29 ; K: A$ ratio $=$ $-0.10 \pm 0.29$; intercept constant $=5.3 \pm 3.1 \mathrm{mM} . / \mathrm{kg}$./day.

$B$. Ketone utilization as a function of total fat catabolism. Correlation $=0.91 \pm 0.05 ; k=0.28 \pm 0.04 ; U_{0}=$ $34.5 \pm 1.4 \mathrm{mM} . / \mathrm{kg} . /$ day. 
$4 A$

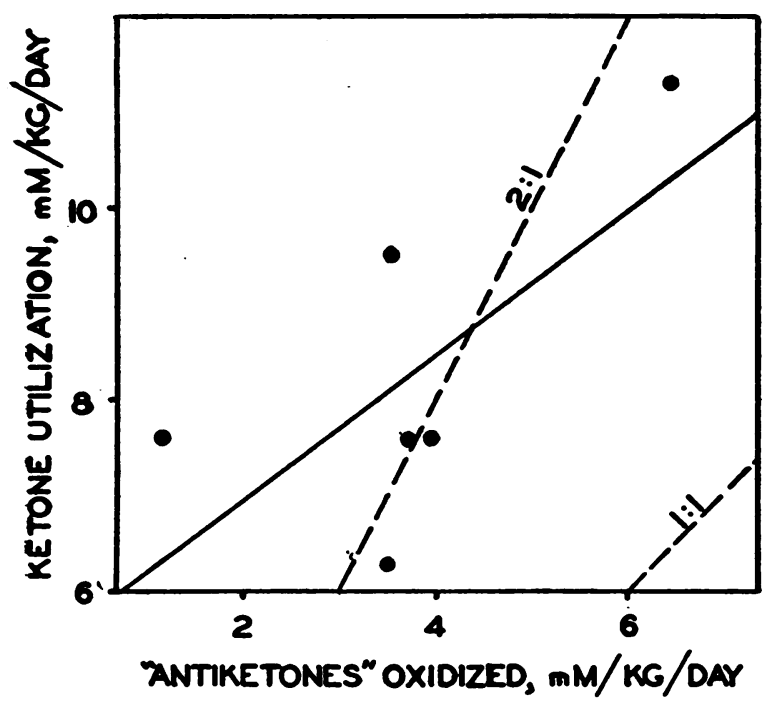

$4 B$

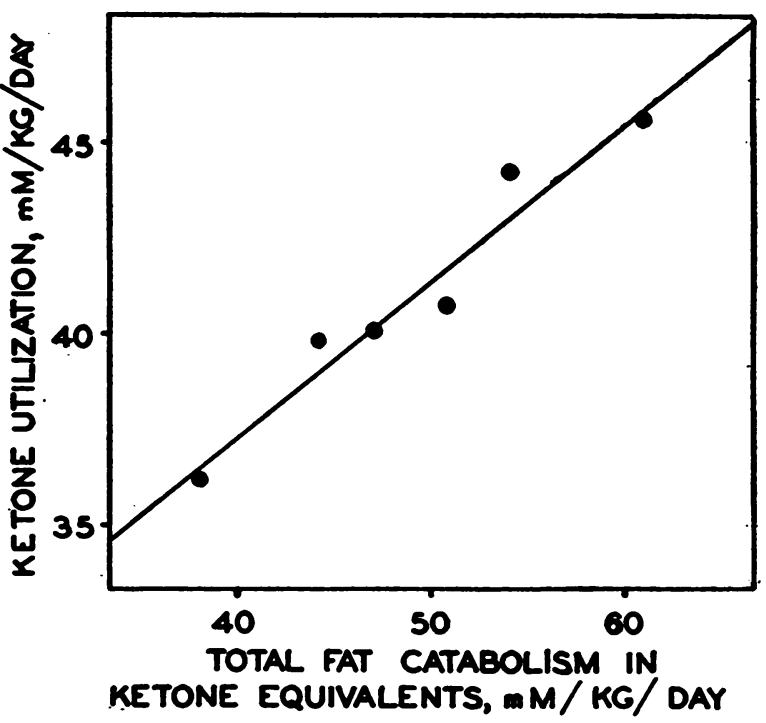

Fig. 4. Diabetes Melurtus, Cyrrl K. (Gephart, Aub, Du Bois, and Lusk, 1917)

$A$. Ketone utilization as a function of " antiketones" oxidized. Correlation $=0.67 \pm 0.27 ; K: A$ ratio $=0.72 \pm$ 0.39 ; intercept constant $=5.6 \pm 1.2 \mathrm{mM} . / \mathrm{kg} . /$ day.

$B$. Ketone utilization as a function of total fat catabolism. Correlation $=0.97 \pm 0.03 ; k=41 \pm 0.05 ; U_{0}=$ $35.4 \pm 1.3 \mathrm{mM} . / \mathrm{kg} . /$ day.

$5 A$

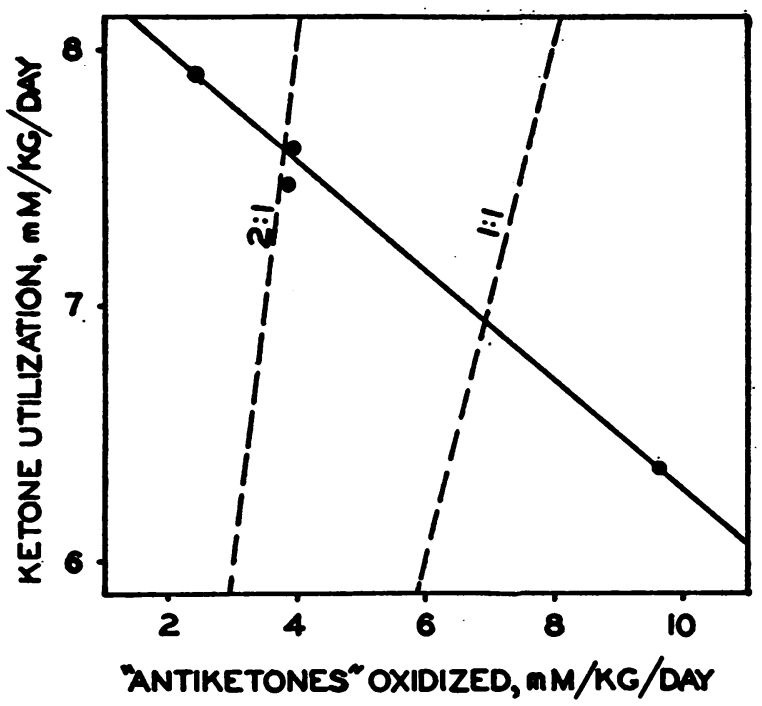

$5 B$

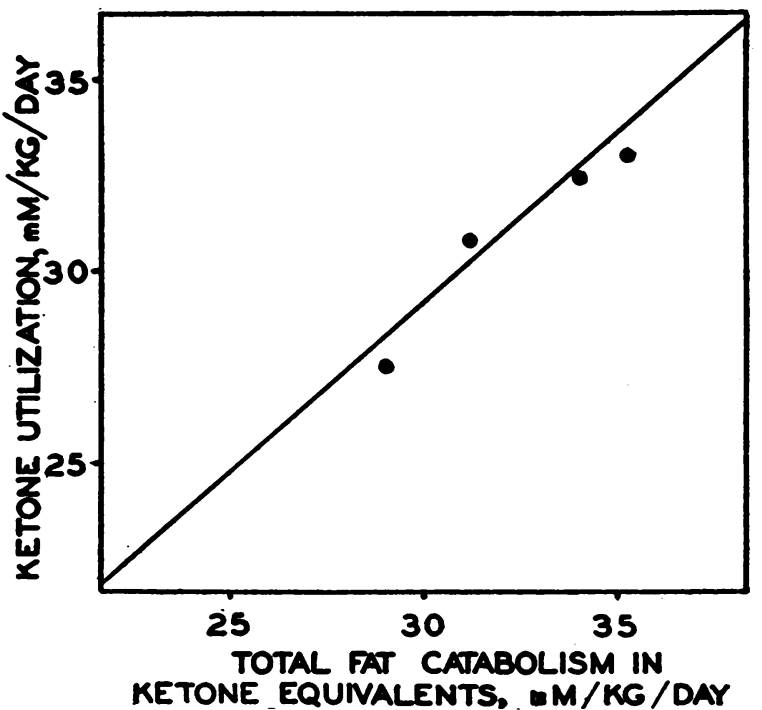

Fig. 5. Diabetes Mellitus, Jervis B. (Richardson and Ladd, 1923)

$A$. Ketone utilization as a function of "antiketones" oxidized. Correlation $=-0.99 \pm 0.01 ; K: A$ ratio $=$ $-0.21 \pm 0.05$; intercept constant $=12.3 \pm 0.1 \mathrm{mM} . / \mathrm{kg} . /$ day.

$B$. Ketone utilization as a function of total fat catabolism. Correlation $=0.97 \pm 0.04 ; k=0.84 \pm 0.14 ; U_{0}=$ $23.2 \pm 1.9 \mathrm{mM} . / \mathrm{kg} . /$ day. 
$6 A$

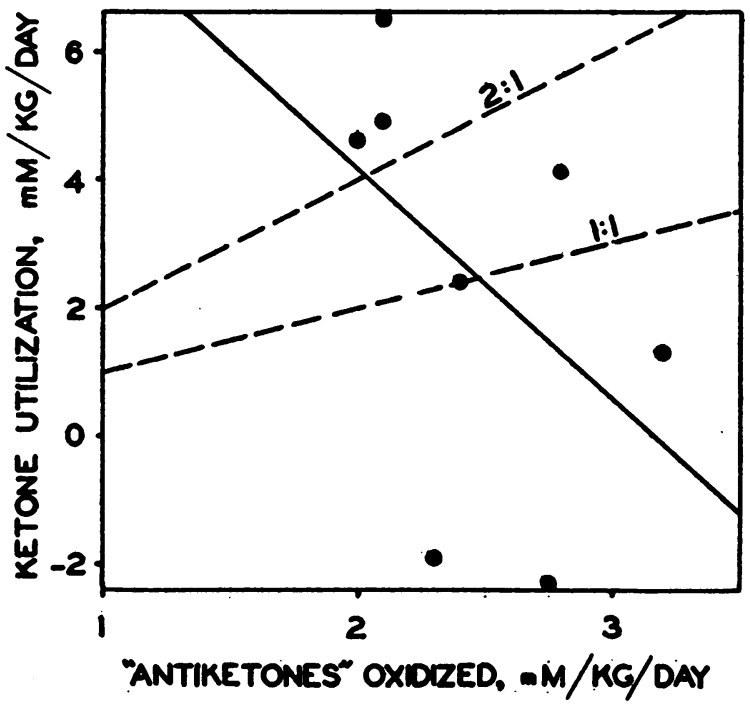

$6 B$

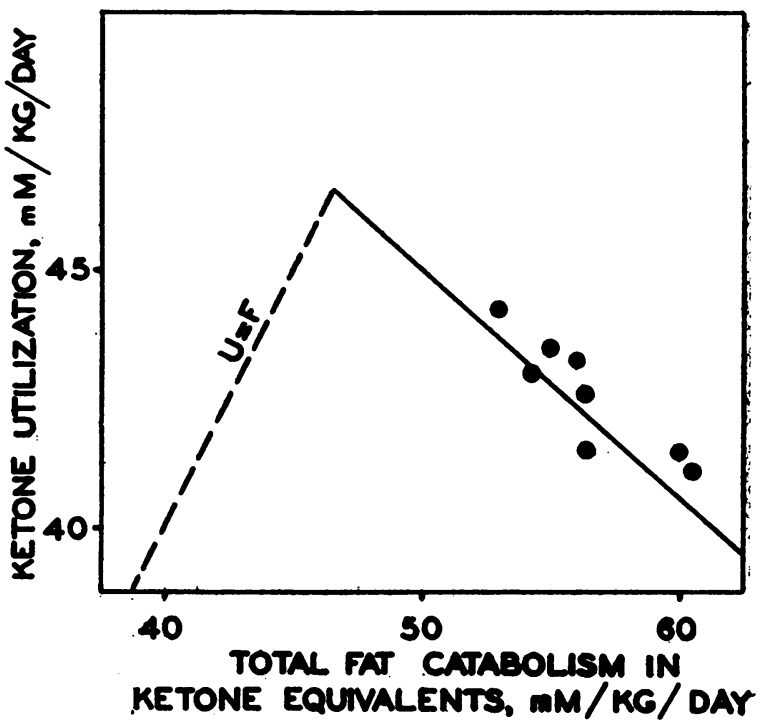

Fig. 6. Diabetes Mellitus, E. W. (Mosenthal and Lewis, 1917)

$A$. Ketone utilization as a function of " antiketones" oxidized. Correlation $=-0.45 \pm 0.33 ; K: A$ ratio $=$ $-3.6 \pm 2.4$; intercept constant $=11.3 \pm 0.8 \mathrm{mM} . / \mathrm{kg} . /$ day.

$B$. Ketone utilization as a function of total fat catabolism. Correlation $=-0.89 \pm 0.08 ; k=-0.38 \pm 0.08$; $U_{0}=46.6 \pm 3.5 \mathrm{mM} . / \mathrm{kg} . / \mathrm{day}$.

is found to be $5.6 \pm 1.2 \mathrm{mM}$. per $\mathrm{kgm}$. per day. In other words, it is practically certain (prob. $=>0.999$ ) that there is utilization of ketones when there is no oxidation of "antiketones." The observations in this case, therefore, do not support the hypothesis.

Jervis B., Diabetes mellitus (26), (Figure 5A). Mild ketonuria (2 to 12 grams per day). There is no significant relation between the observed points and the dashed lines calculated for $r=1$ or 2 . There is a negative correlation $(-0.99 \pm 0.01)$. The statistical line shows a greater utilization of fat as the carbohydrate oxidation (" antiketones") is diminished.

E. W., Diabetes mellitus (27), (Figure 6A). Severe ketonuria (65 to 11 grams of beta hydroxybutyric acid per day). There is a negative correlation ( $-0.45 \pm$ 0.33) giving a negative $r=-3.6 \pm 2.4$, a value which has no meaning with respect to the hypothesis under discussion. The theoretical lines for $r=1$ or 2 bear no significant relation to the observed points. When ketone formation is calculated on the old $1: 1$ basis, there is found in this case on two occasions a ketone body excretion which exceeded the calculated ketone body formation. A similar observation was found in the case of Kramer.

\section{Hypothesis of fat metabolism in the diabetic}

In summary, it is apparent from this analysis that there is no significant relation between the ketone bodies utilized and the "antiketones" oxi- dized. The hypothesis of obligatory coupling of ketone body-carbohydrate oxidation in the diabetic receives no support from the quantitative data in this series of cases of diabetes mellitus. It remains, therefore, to formulate an hypothesis which will be in conformity with the observations.

The following appears to fulfill these requirements :

$U p$ to a certain level fat metabolism is complete and there is no ketonuria. Beyond this level fat metabolism is incomplete and part of the fat catabolized is excreted in the form of ketone bodies.

The relation of carbohydrate to fat metabolism is an inverse one: the greater the carbohydrate metabolism, the less is the fat metabolism. There is no fixed relation in the sense of a definite molecular ratio of ketogenic: antiketogenic substances.

The hypothesis is elaborated in the form of a diagram (Figure 7) and an equation:

Let $F=$ total fat catabolized in grams, mM., or equivalent $\mathrm{mM}$. of ketone bodies.

$U=$ total fat utilized in grams, mM., or equivalent $\mathrm{mM}$. of ketone bodies.

$U_{o}=$ maximal aketonuric fat utilization. 


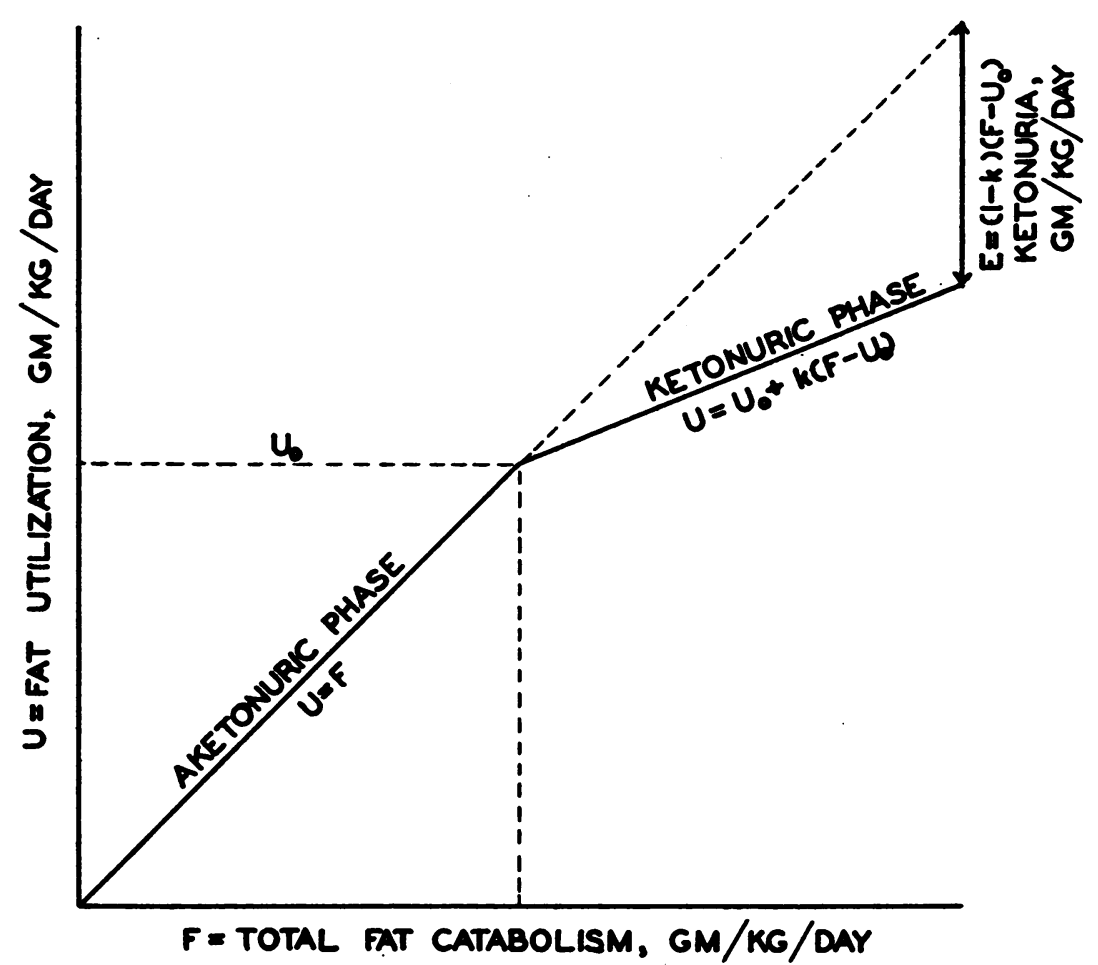

Fig. 7. Schematic Representation of Fat Metabolism in Diabetes Mellitus

The figure embodies the hypothesis discussed in the text. The equations relating fat utilization and ketonuria to total fat catabolism are shown in the graph. $F=$ total fat catabolized; $U=$ total fat utilized; $U_{0}=$ maximal aketonuric fat utilization; $E=$ total urinary ketone bodies; $k=$ coefficient of excess fat utilization.

$E=$ total urinary ketone bodies in $\mathrm{mM}$. of ketone bodies or the equivalent grams of mM. of " original" fat.

$k=$ " coefficient of excess fat utilization."

In any given calculation all of the above terms must be expressed in the same units. The conversion factors necessary are:

1 gram of fat

$$
\begin{aligned}
& =\frac{1000}{870}=1.15 \mathrm{mM} . \text { of fat. } \\
& =\frac{1000}{870} \times 12=13.8 \mathrm{mM} \text {. of ketone bodies. }
\end{aligned}
$$

$1 \mathrm{mM}$. of ketone bodies $=\frac{1}{12} \frac{870}{1000}$

$$
\begin{aligned}
& =0.0726 \text { grams “ original " fat. } \\
& =0.0836 \mathrm{mM} \text {. of " original " fat. }
\end{aligned}
$$

$870=$ molecular weight average fat (triglyceride). ${ }^{5}$

The balance of the total metabolism not represented by carbohydrate or protein is, of course, represented by fat metabolism. Part or all of the total fats catabolized undergo a preliminary partial oxidation in the liver to acetoacetic or beta hydroxybutyric acids. The ketone bodies (or fat itself) are utilized in the peripheral tissue by both normal and diabetic subjects without chemical coupling with carbohydrate oxidation. Up to a certain point, catabolism keeps exact pace with the body's need for energy from fat and there is no ketonuria. We may express this by saying that $U=F$ and represent it on the diagram (Fig-

5 In accordance with the multiple alternate oxidation hypothesis, these conversion factors are calculated on the assumption that 1 molecule of fatty acid yields 4 molecules of ketone bodies. 
ure 7) as the first or aketonuric phase of fat metabolism. When, however, at a given state of activity the need for fat metabolism exceeds a certain maximal aketonuric utilization value $\left(U_{0}\right)$ fat is catabolized in excess of utilization. The excess of fat catabolism over the aketonuric level is divided into two parts: (1) the $k$ th part is utilized as extra fat utilization; (2) the $(1-k)$ th part is excreted in the form of urinary ketone bodies. Therefore, in this second or ketonuric phase the fat metabolism is represented by the equation:

$$
U=F-E=U_{o}+k\left(F-U_{o}\right)
$$

and the urinary ketone bodies are given by the equation :

$$
E=(1-k)\left(F-U_{0}\right)
$$

\section{Application of the equation to the cases}

The cases cited in Group I all had moderate to severe ketonuria. In other words $F>U_{0}$. Equation 2 may then be applied to the data. In the figures ( 1 to 6 ) (1) already given, the $B$ segments show the data plotted in this way. In the conversion of the fat of the metabolic mixture to equivalent amounts of ketone bodies the ratio of four molecule of ketone bodies per molecule of fatty acid was assumed in accordance with the multiple alternate oxidation hypothesis. The statistical calculations are shown in the figures. In a series of cases (Group II) in which ketonuria was relatively low ( $=<5$ grams per day) or where there are but a few observations, the value of $U_{0}$ has been calculated directly (Equation 2). These values have been included in the summarizing table (Table VI).

Inspection of Figures $1 B$ to $6 B^{\circ}$ and of Table VI shows the following:

1. The cases of Group I show in every case a high correlation between $U_{o}$ and $F$, indicating that

${ }^{6}$ The labelling of the ordinates in these figures as "Ketone utilization" and "Total fat metabolism in ketone equivalents" does not imply that 100 per cent of the fat catabolized goes through the ketone body stage. The proportion which does is not known ( $C f$. section on "Direct and indirect fat metabolism"). The terms "Fat utilization" and "Total fat catabolism" could just as well have been used as they are in Figure 9. The present terms are used here to emphasize the relation between fat catabolism expressed as ketones and potential ketone utilization.
TABLE VI

Summary of maximal basal aketonuric fat utilization

\begin{tabular}{|c|c|c|c|}
\hline Case & Reference & $\begin{array}{c}\text { Marimal aketonuric } \\
\text { fat utilization in } \\
\text { equivalents of ketone } \\
\text { bodies }\end{array}$ & $\begin{array}{l}\text { Coeffi- } \\
\text { cient of } \\
\text { excess } \\
\text { fat } \\
\text { utiliza- } \\
\text { tion }\end{array}$ \\
\hline $\begin{array}{l}\text { Group I } \\
\text { Cyril K... } \\
\text { Bessie B... } \\
\text { Kramer... } \\
\text { 740...... } \\
\text { E. W..... } \\
\text { Jervis B... } \\
\text { Group II } \\
\text { Ray H.... } \\
\text { Chris. Q... } \\
\text { Harold J.. } \\
\text { George H.. } \\
\text { Frank B... } \\
\text { K. A...... }\end{array}$ & $\begin{array}{l}\text { Gephart, Aub, DuBois } \\
\text { and Lusk (25) } \\
\text { Wilder, Boothby and } \\
\text { Beeler(24) } \\
\text { Shaffer (22) } \\
\text { Joslin (23) } \\
\text { Mosenthal and Lewis (27) } \\
\text { Richardson and Ladd (26) } \\
\\
\text { Richardson and Ladd (26) } \\
\text { Richardson and Ladd(26) } \\
\text { Richardson and Ladd(26) } \\
\text { Richardson and Ladd (26) } \\
\text { Richardson and Ladd(26) } \\
\text { McClelland, Spencer, and } \\
\text { Falk (28) }\end{array}$ & $\begin{array}{c}\text { mM. per kgm. per day } \\
35 \\
34 \\
35 \\
28 \\
(47) \\
23 \\
\\
\\
37 \\
26 \\
37 \\
37 \\
37 \\
40\end{array}$ & $\begin{array}{l}+0.41 \\
+0.75 \\
+0.28 \\
+0.75 \\
+0.38 \\
+0.84\end{array}$ \\
\hline & $\begin{array}{l}\text { Mean (11 cases) } \\
\text { Equivalent in grams } \\
\text { of fat }\end{array}$ & \multicolumn{2}{|c|}{$\begin{array}{l}34 \pm 1.6 \text { (S. E. of mean) } \\
2.5 \pm 0.12\end{array}$} \\
\hline
\end{tabular}
in cases of diabetes mellitus

* Excluded from basal mean on account of fever $\left(102^{\circ} \mathrm{F}\right.$.).

utilization of fats by the diabetic is a function of the total fat catabolism.

2. The values for $U_{o}$, the maximal basal aketonuric fat utilization, are all concordant (except E. W., $v$. infra). The mean value was found to be $2.5 \pm 0.12$ grams of fat per $\mathrm{kgm}$. per day equivalent to $34 \pm 1.6 \mathrm{mM}$. of ketone bodies per $\mathrm{kgm}$. per day. This value is in essential agreement with the mean basal ketone utilization (32 $\pm 3.1 \mathrm{mM}$. of ketone bodies per $\mathrm{kgm}$. per day, Table IV) found in the experimental animal by different workers and by different methods.

These findings are considered to constitute proof that the hypothesis concerning fat metabolism in diabetes mellitus already stated is in conformity with the quantitative data available in the literature.

\section{Significance of the coefficient of excess fat utilization}

It will be observed (Table VI) that the value of $k$, which we have called the coefficient of excess fat utilization, varies considerably among the six cases with sufficient data for its calculation. The significance of this is that some subjects (with high value of $k$ ) are able to utilize excess fat without an undue increase of ketonuria. Those 
with low $k$ values are only able to increase their total calories from fat at the cost of a relatively heavy increase of ketonuria. Whether this division of diabetics into two classes on the basis of their $k$ values has any bearing on the problem of high fat versus low fat in the dietary cannot be said.

Fat metabolism in febrile severe diabetic (Mosenthal and Lewis' E. W.)

This case had three features which are in contrast to those of the other cases:

1. Fever, $102^{\circ} \mathrm{F}$. (Infected foot ulcer.)

2. High aketonuric fat utilization level, $46.6 \pm 3.5$ mM. per kgm. per day ketone bodies.

3. Severe ketonuria (approximately 8 to $20 \mathrm{mM}$. per $\mathrm{kgm}$. per day of beta hydroxybutyric acid).

4. Negative value of $k$, the coefficient of excess fat utilization.

Since there is only one case in the series showing these peculiarities, discussion is speculative, but it may be that this case represents an extreme type of fat metabolism, possibly characteristic of the febrile severe diabetic. The well known clinical fact that infection superimposed upon severe diabetes leads to sharp increase of ketonuria could then be reasonably explained as follows : unlike the afebrile diabetic who can increase his fat utilization above the aketonuric level ( $k$ positive), the febrile diabetic has a decreased "tolerance" for fat ( $k$ negative) as well as carbohydrate. In consequence, without appreciable change in total fat catabolism there is a sharp fall of fat utilization below the aketonuric utilization level accompanied necessarily by an increase of ketone body excretion.

\section{Fat utilization in exercise}

For basal conditions, $U_{o}$ per unit of body weight will be constant and within limits should be the same for different subjects. As discussed in the introduction, the peripheral tissues are capable of oxidizing ketone bodies at a rate equivalent to 5 to 7 times the basal metabolic needs. It has also been well established that in the completely diabetic depancreatized animals or in severe diabetes mellitus, there is essentially no change of ketone body excretion during exercise.
From equation (3) the ketone excretion is:

$$
E=(1-k)\left(F-U_{o}\right) \text {. }
$$

Therefore, for two states of activity, basal and working, if we assume that $k$ does not change, we get:

$$
\Delta F=\Delta U_{o}
$$

The meaning of this is clear: during exercise the increase of utilization keeps pace with increased fat catabolism. This conclusion seems to be a simple explanation of the non-increase of ketonuria in the diabetic during exercise; whereas, as has been previously pointed out, this nonincrease is entirely incompatible with the obligatory coupling hypothesis.

\section{Ketonuria in diabetes mellitus}

We have preferred to discuss the problem of fat metabolism in diabetes mellitus in terms of utilization rather than in terms of urinary ketone bodies in order to emphasize ketone body oxidation rather than excretion. However, it is equally possible to show that the data on ketonuria in diabetes conform to the hypothesis. By the transformation of the equation (3) we obtain:

$$
E=(1-k)\left(F-U_{0}\right) \text {. }
$$

By way of illustration, the data in one case are plotted in Figure 8 and the points may be compared with the line calculated, using the constants already found. It is obvious that the relations hitherto described predict the course of ketonuria in the diabetic with precision.

It might also be emphasized that the information obtained from observations on ketonuria per $s e$ is limited. For ketone body formation may vary within wide limits up to utilization $=U_{0}$ without any ketonuria. Above this value the exact relation between formation and excretion cannot be determined unless the value of the " coefficient of excess utilization," which varies widely from subject to subject, is also known.

\section{Direct and indirect fat metabolism}

The proportion of the total fat metabolism represented by $(a)$ preliminary partial oxidation in the liver to ketone bodies followed by oxidation of the ketone bodies in the periphery, and (b) 


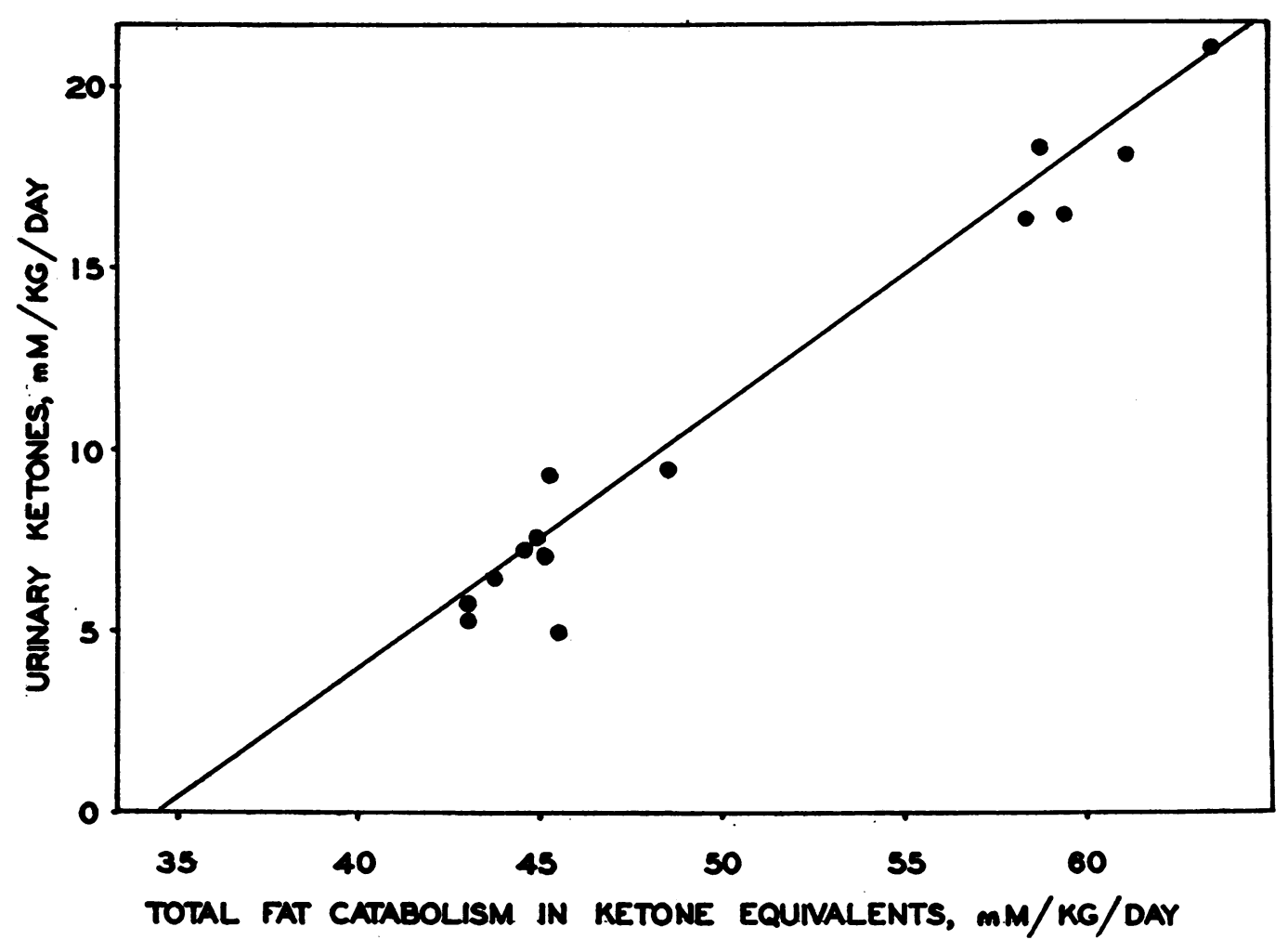

Fig. 8. Diabetes Mellitus, Kramer (Shaffer, 1922)

Urinary ketone body excretion as a function of the total fat catabolism. $E=(1-k)\left(F-U_{o}\right)$. Correlation $=0.99 \pm 0.01 ; k=0.28 \pm 0.03 ; U_{o}=35.3 \pm 1.3 \mathrm{mM} . / \mathrm{kg} . /$ day.

direct oxidation initiated and completed in the periphery, remains undetermined. There appears to be no doubt that ketone body utilization in the periphery may be sufficient to account for 4 to 6 times the basal requirements of the animal. But whether the liver does in fact partially oxidize such large amounts of fat is doubtful. For example, Stadie, Zapp, and Lukens (15a) found, with liver slices from depancreatized cats, ketone body formation equivalent to $1.3 \mathrm{mM}$. per $\mathrm{kgm}$. per body weight per hour. But the total basal metabolism of the depancreatized cat, which must be largely that of fat, when expressed as ketone bodies is equivalent to approximately $4.5 \mathrm{mM}$. per $\mathrm{kgm}$. per hour (calculated from data of Ring and Hampel (29)). Apparently only about 30 per cent of the total fat metabolism could be accounted for by the mechanism of preliminary oxidation to ketone bodies in the liver followed by complete oxidation in the periphery. In the normal fasted ( 2 to 4 days) cats they found still lower values, viz., about 10 per cent. In a series of fasted phlorhizinized rats, hepatic ketone body formation was found to represent not more than 10 to 15 per cent of the estimated total basal metabolism (10).

\section{The relation of hepatic and muscle respiratory metabolism}

Another difficulty in the problem of fat metabolism which has not been sufficiently emphasized in the literature arises from a consideration of the oxygen requirements of the liver for the preliminary partial oxidation of fats to muscle substrates such as acetoacetate. From the observations of Barcroft and Kato (30) on the oxygen uptake of the gastrocnemius of the $d o g$ in the resting state and during stimulation at the rate of 60 times per second, the data shown in table VII have been calculated.?

7 Barcroft and Kato's results may be too high. (Compare, for example, Himwich and Rose (33).) However, cutting their values in half would not influence the main argument here. 
TABLE VII

Observed muscle and calculated hepatic metabolism of resting and exercising dog

For case: 100 per cent preliminary hepatic partial oxidation of fats to acetoacetic acid

\begin{tabular}{l|c|c|c}
\hline \hline & $\begin{array}{c}\text { Calculated } \\
\text { Observed } \\
\text { oxygen uptake } \\
\text { by muscle* }\end{array}$ & $\begin{array}{c}\text { Calculated } \\
\text { equivalent } \\
\text { amount of } \\
\text { acetoacetate } \\
\text { oxidized by } \\
\text { muscle }\end{array}$ & $\begin{array}{c}\text { uptake requgen } \\
\text { for production } \\
\text { of acetoactate } \\
\text { from fat by } \\
\text { partial oxidation } \\
\text { in liver }\end{array}$ \\
\hline Resting..... & $\begin{array}{c}\text { per gram } \\
\text { of muscle } \\
\text { micromoles } \\
\text { per hour }\end{array}$ & $\begin{array}{c}\text { pod kgm. } \\
\text { boeight } \\
\text { millimoles } \\
\text { per hour }\end{array}$ & $\begin{array}{c}\text { per gram } \\
\text { of liver } \\
\text { micromoles } \\
\text { per hour }\end{array}$ \\
\hline Exercising .. & 166 & $\begin{array}{c}4.6 \\
16.6\end{array}$ & 268 \\
\hline Difference .. & 120 & 12.0 & 7008 \\
\hline
\end{tabular}

Conversion factors:

For total combustion in muscle: 1 mole $0_{2}=1 / 4$ mole acetoacetate.

For partial oxidation of fat in liver: 1 mole acetoacetate $=1.75$ moles $0_{2}$.

Assume:

400 grams of muscle per $\mathrm{kgm}$. body weight. 30 grams liver per $\mathrm{kgm}$. body weight.

* Original data of Barcroft and Kato (30).

The table illustrates the expectation in the hypothetical case in which the entire muscular metabolism is dependent upon indirect fat utilization, i.e., one in which there is a preliminary partial oxidation of fat by the liver to acetoacetate. It will be noted that the increase, due to exercise, of the oxygen uptake per unit weight is some six times greater in the case of the liver than in the case of the muscle. Furthermore, these calculated hepatic respirations both in the resting and working state are greatly in excess of observed oxygen uptakes. For example, the observations of Staub (31) on perfused livers of dogs give a mean value of about 70 micromoles per gram of liver per hour for the oxygen uptake. In the intact cat Barcroft and Shore (32) found somewhat lower values. Innumerable observations of liver slices in vitro give a value of 75 to $100 \mathrm{uM}$. per gram per hour. These values are about $1 / 3$ of the basal requirements and about $1 / 10$ of the requirements under exercise calculated in the table. It is, of course, impossible to say that these intense hepatic respirations cannot be attained by the liver in vivo, but the marked discrepancy between the observed values (unless these are con- sidered to be in gross error) and those calculated on the basis of complete indirect fat metabolism must be taken into consideration in interpreting the problem of fat metabolism.

The difficulties discussed in the last two sections can be overcome by supposing that a considerable part of the fat metabolism of muscle occurs directly, i.e., without preliminary hepatic partial oxidation to ketone bodies. The evidence on this point is not unequivocal. For example, Gemmill (34), who reviews the recent literature on this subject, was unable to find any diminution of fat in the working muscle of the normal or phlorhizinized rat, and he concluded that when fat is used to supply energy for work in mammalian muscle, it is used indirectly. However, in view of the many observations of respiratory quotients ranging from 0.7 to 0.8 , in the case of muscle with intact blood supply, or isolated perfused muscle (33), or muscle equilibrated in vitro, the possibility of direct utilization of fat cannot be excluded. The extreme view, held by some physiologists, that carbohydrate only can be oxidized by muscle appears no longer tenable.

\section{Schematic representation of total metabolism in the diabetic}

The relation of ketonuria to the fat metabolism and the total metabolism elicited by the study of these cases of diabetes mellitus can be incorporated into a scheme (Figure 9) which is intended to show the interrelations of these factors only in a general way. It is not a nomogram for application to specific cases. For simplicity, assume a case to be without glycosuria deriving 20 per cent of the caloric needs from protein. Then

\subsection{Total calories \\ $=$ Fat calories + Carbohydrate calories}

The figure is based upon this equation and the necessary conversion factors. Several points of interest are shown by the diagram:

1. Ketonuria is avoided if the fat catabolized is equal or less than about 2.5 grams per kgm. per day. It must be remembered that this value is for the resting state and may be higher during states of activity.

2. When the caloric metabolism is low, keton- 


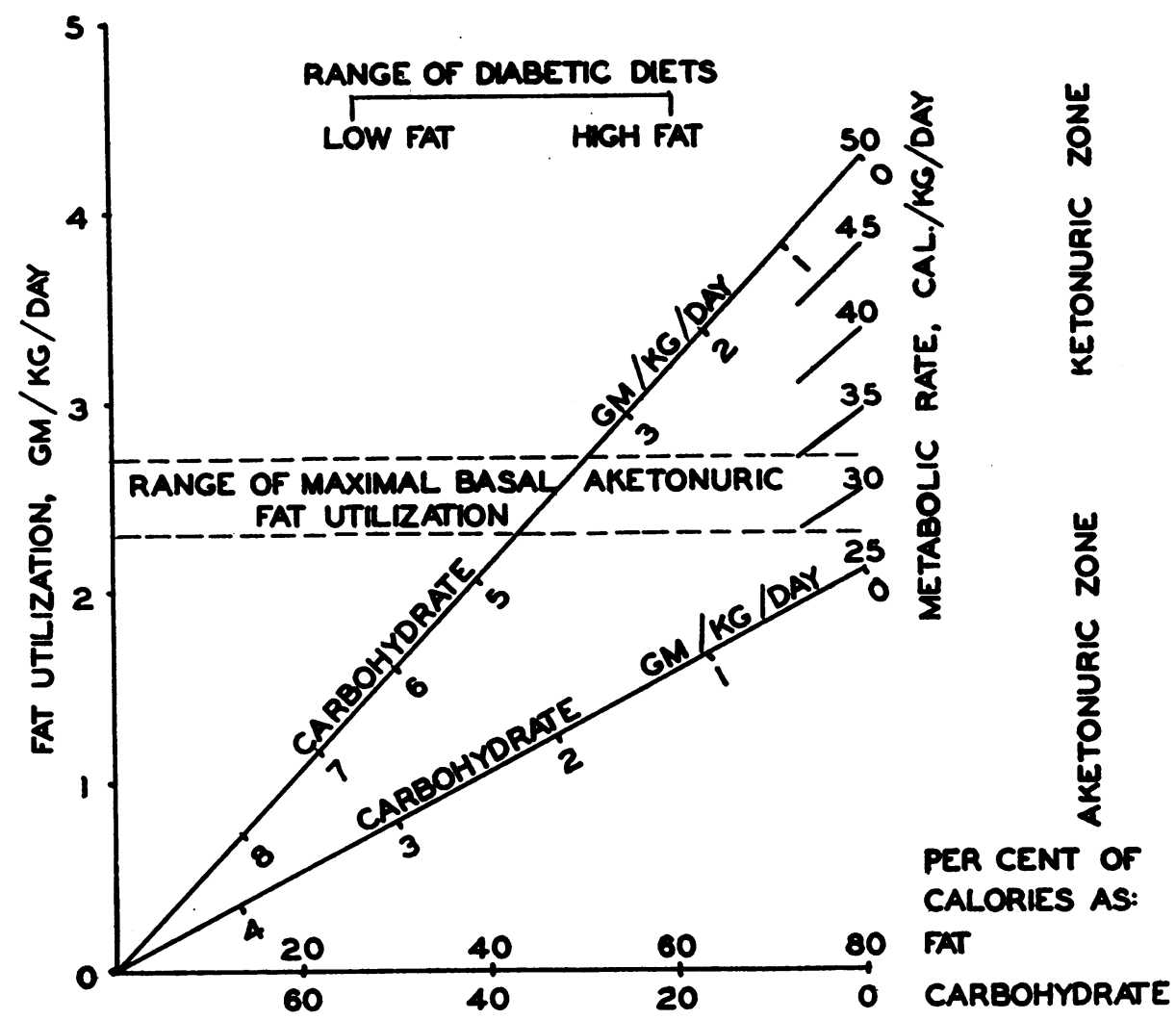

Fig. 9. Schematic Representation of Carbohydrate and Fat Metabolism in Diabetes Meluitus and Their Relation to Ketone Body Excretion

uria may be absent even when the carbohydrate metabolized is quite low.

3. The greater the caloric needs, the greater must be the proportion of carbohydrate in the metabolic mixture in order to avoid ketonuria.

4. The diets which through clinical experience have been recommended in the literature are, with respect to their proportions of carbohydrate and fat, essentially of the type which avoid ketonuria.

\section{SUM MARY}

1. The problem of fat metabolism in diabetes mellitus and its relation to ketonuria is reviewed and discussed.

2. Evidence favoring the replacement of the successive beta oxidation hypothesis of fatty acids by the multiple alternate oxidation hypothesis is presented.

3. It is shown that the diabetic animal utilizes ketone bodies in the periphery abundantly and independently of carbohydrate oxidation.
4. The hypothesis of obligatory coupling of ketone body-carbohydrate oxidation in diabetes mellitus is not supported by the quantitative data in a series of cases.

5. A simple hypothesis of fat metabolism in diabetes mellitus is presented and shown to conform to the observations in these cases.

6. Other significant problems in fat metabolism are discussed.

\section{BIBLIOGRAPHY}

1. Knoop, F., Der Abbau aromatischer Fettsäuren im Tierkörper. Beitr. z. chem. Phys. u. Path., 1904, $6,150$.

2a. Dakin, H. D., The mode of oxidation in the animal organism of phenyl derivatives of fatty acids. Part V. J. Biol. Chem., 1909, 6, 221.

b. Dakin, H. D., Physiological oxidations. Physiological Rev., 1921, 1, 394.

3. Friedmann, E., Zur Kentniss des Abbaues der Karbonsāuren im Tierkörper. XVII. Ueber die Bildung von Acetessigsäure aus Essigsäure bei der Leberdurchblutung. Biochem. Ztschr., 1913, 55, 436. 
4. von Fürth, O., The Problems of Physiological and Pathological Chemistry of Metabolism. Transl. by Allen J. Smith. Lippincott, Philadelphia, 1916, p. 439.

5. Raper, H. S., and Smith, E. C., Insulin and the production of acetone bodies by the perfused liver. J. Physiol., 1926, 62, 17.

6. Chaikoff, I. L., and Soskin, S., Utilization of acetoacetic acid by normal and diabetic dogs before and after evisceration. Am. J. Physiol., 1928, 87, 58.

7. Mirsky, I. A., Nelson, N., and Grayman, I., The utilization of acetone bodies. I. The influence of feeding and of glucose in nephrectomized female rats. J. Biol. Chem., 1939, 130, 179.

8a. Blixenkrone-Mфller, N., Respiratorischer Stoffwechsel und Ketonbildung der Leber. Ztschr. f. Physiol. Chem., 1938, 252, 117.

b. Blixenkrone-M $\phi$ ller, N., Kohlenhydrat- und Ketonkörperbildung aus Fettsäuren in der künstlich durchströmten Katzenleber. Ibid., 137.

9. Weil-Malherbe, H., The formation of glucose from acetoacetic acid in rat kidney. Biochem. J., 1938, 32, 2276.

10. Stadie, W. C., Zapp, J. A., Jr., and Lukens, F. D. W., J. Biol. Chem. (In press, Dec. 1940).

11. Hurtley, W. H., The four carbon atom acids of diabetic urine. Quart. J. Med., 1916, 9, 301.

12. Barker, S. B., The effects of increased metabolism on ketosis of depancreatized dogs. J. Physiol., 1940, 97, 394.

13. Jowett, M., and Quastel, J. H., Studies in fat metabolism. I. The oxidation of butyric, crotonic, and $\beta$-hydroxybutyric acids in the presence of guineapig liver slices. Biochem. J., 1935, 29, 2143.

14. Deuel, H. J., Jr., Hallman, L. F., Butts, J. S., and Murray, S., Studies on ketosis. VIII. Quantitative studies on the oxidation of ethyl esters of the fatty acids. J. Biol. Chem., 1936, 116, 621.

15a. Stadie, W. C., Zapp, J. A., Jr., and Lukens, F. D. W., The effect of insulin upon the ketone metabolism of normal and diabetic cats. J. Biol. Chem., 1940, $132,423$.

b. Stadie, W. C., Zapp, J. A., Jr., and Lukens, F. D. W., The fatty acid metabolism of the liver of the diabetic cat. J. Biol. Chem. (Proc.), 1940, 133, xcvi.

16. Stetten, DeW., Jr., and Schoenheimer, R., The conversion of palmitic acid into stearic and palmitoleic acids in rats. J. Biol. Chem., 1940, 133, 329.

17. Cori, C. F., Symposium on carbohydrate metabolism; glycogen breakdown and synthesis in animal tissues. Endocrinology, 1940, 26, 285.

18. Mitchell, H. H., The possibility of the conversion of fatty acids to glucose in the animal body. J. Nutrition, 1933, 6, 473.
19. Soskin, S., The liver and carbohydrate metabolism. Endocrinology, 1940, 26, 297.

20. Friedemann, T. E., The metabolism of sodium acetoacetate intravenously injected into dogs. J. Biol. Chem., 1936, 116, 133.

21. Dye, J. A., and Chidsey, J. L., Ketone body-total carbohydrate utilization ratios and their relation to the problem of ketosis. Am. J. Physiol., 1939, 127, 745.

22. Shaffer, P. A., Antiketogenesis. IV. The ketogenicantiketogenic balance in man and its significance in diabetes. J. Biol. Chem., 1922, 54, 399.

23. Joslin, E. P., Present-day treatment and prognosis in diabetes. Am. J. M. Sc., 1915, 150, 485.

24. Wilder, R. M., Boothby, W. M., and Beeler, C., Studies of the metabolism of diabetes. J. Biol. Chem., 1922, 51, 311.

25. Gephart, F. C., Aub. J. C., Du Bois, E. F., and Luck, G., Clinical calorimetry. XXIV. Metabolism in three unusual cases of diabetes. Arch. Int. Med., $1917,19,908$.

26. Richardson, H. B., and Ladd, W. S., Clinical calorimetry. XXXIV. Ketosis and the respiratory exchange in diabetes. J. Biol. Chem., 1924, 58, 931.

27. Mosenthal, H. O., and Lewis, D. S., The D: N ratio in diabetes mellitus. Bull. Johns Hopkins Hosp., 1917, 28, 187.

28. McClellan, W. S., Spencer, H. J., Falk, E. A., and Du Bois, E. F., Clinical calorimetry. XLIII. A comparison of the thresholds of ketosis in diabetes, epilepsy, and obesity. J. Biol. Chem., 1928, 80, 639.

29. Ring, G. C., and Hampel, C. W., The respiratory metabolism of pancreatic diabetes in cats. Am. J. Physiol., 1932, 102, 460.

30. Barcroft, J., and Kato, T., Effects of functional activity in striated muscle and the submaxillary gland. Phil. Trans. Roy. Soc., London, Ser. B, 1915-1916, 207, 149.

31. Staub, H., Gaswechsel- und Bilanzversuche an der isoliert durchströmten innervierten oder nicht innervierten Leber. III. Ueber Leberstoffwechsel. Arch. f. Exper. Path. u. Pharm., 1931, 162, 433.

32. Barcroft, J., and Shore, L. E., The gaseous metabolism of the liver. I. In fasting and late digestion. J. Physiol., 1912-13, 45, 296.

33. Himwich, H. E., and Rose, M. I., Studies in the metabolism of muscle. II. The respiratory quotient of exercising muscle. Am. J. Physiol., 1929, 88, 663.

34. Gemmill, C. L., The effect of stimulation on the fat and carbohydrate content of gastrocnemius muscle in the phlorizinized rat. Bull. Johns Hopkins Hosp., 1940, 66, 71. 